\title{
PENGARUH BUDAYA KERJA TERHADAP EFEKTIVITAS PELAYANAN PUBLIK KANTOR DESA TIMORENG PANUA KECAMATAN PANCA RIJANG KABUPATEN SIDENRENG RAPPANG
}

\author{
Cakra \\ Fakultas IImu Sosial dan IImu Politik Universitas Muhammadiyah Sidenreng Rappang \\ cakra43152004a1@gmail.com
}

\begin{abstract}
Abstrak
Penelitian ini bertujuan untuk mengetahui Pengaruh Budaya Kerja terhadap Efektivitas Pelayanan Publik di Kantor Desa Timoreng Panua Kecamatan Panca Rijang Kabupaten Sidenreng Rappang. Populasi dalam penelitian ini adalah seluruh Kartu Keluarga (KK) berjumlah 547 Kartu Keluarga dari 2 Dusun. Pengambilan sampel pada penelitian ini menggunakan sampel acak dengan menggunakan Rumus Yount dengan taraf kesalahan 10\%, sehingga menghasilkan sampel sebanyak responden. Teknik pengumpulan data dalam penelitian ini adalah observasi, kuesioner, wawancara dan studi pustaka. Data yang terkumpul dianalisis dengan menggunakan tabel distribusi frekuensi dan regresi linear sederhana dengan bantuan Program SPSS 16.0. Hasil penelitian menunjukkan bahwa budaya kerja terhadap efektivitas pelayanan publik di kantor Desa Timoreng Panua Kecamatan Panca Rijang Kabupaten Sidenreng Rappang memiliki pengaruh yang signifikan melihat dari hasilperhitungan pada tabel ANOVA, nilai $t$ Hitung $>t$ Tabel atau $8,262>$ 2,672 dengan tingkat signifikansi $0,000<0,05$, maka keputusannya adalah Ho ditolak dan $\mathrm{Ha}$ diterima, artinya budaya kerja (X)berpengaruh signifikan terhadap efektivitas pelayanan publik $(\mathrm{Y})$. Sedangkan tabel model summary menunjukkan bahwa besar pengaruh budaya kerja $(\mathrm{X})$ terhadap efektivitas pelayanan publik (Y) sebesar 0,563 56,3\%, kategori "cukup berpengaruh". Adapun faktor-faktor yang memengaruhi budaya kerja dilihat dari faktor yang pertama kebersamaan memiliki pengaruh sebesar $23,3 \%$. Faktor yang kedua intensitas memiliki pengaruh sebesar $30,2 \%$.
\end{abstract}

Kata Kunci: Budaya kerja, Efektivitas pelayanan publik

\section{Abstract}

The purpose of this research is to determinate the effect of work culture on the effectiness of public service in the office village of Timoreng Panua, Panca Rijang district, Sidenreng Rappang Regency. The populations of this research is the whole of Family card as much as 547 of 2 hamlets at Timoreng Panua village. The Collecting of Samples using Random Sampling technique and Yount Formula with 10\% Standar error, resulting in a sample as much as 5555 respondents. The data collecting technique of this research is observation, questionnaire, interview and library research. The data analysis of the research used the frecuency distribution tables and simple linaer regresion with SPSS (Statistical Product and Service Solution) 16.0 program for windows. The results showed that the work culture of the effectiveness of public services in the office village ofTimorengPanua,PancaRijang District, SidenrengRappangRegency had a significant influence from the results of calculations in the ANOVA table, $t$ count $>t$ Table or 8.262> 2.672 with a significance level of $0,000<0,05$, then the decision is Ho "refused" and Ha "accepted", meaning that work culture $(X)$ has a significant influential on the effectiveness of public service (Y). While the model summary table shows that the influence of work culture $(X)$ on the effectiveness of public service $(Y)$ is 0.563 or $56.3 \%$ the category "quite influential". The factors that influence work culture are seen from the first factor that togetherness has an influence of $23.3 \%$. The second factor of intensity has an influence of $30.2 \%$.

Keywords : Work Culture, Effectiveness of Public Service.

PRAJA| Volume 8 | Nomor 2 | Edisi Juni 2020 


\section{A. PENDAHULUAN}

Menghadapi era Globalisasi yang penuh tantangan dan peluang, aparat negara yang bertugas melaksanakan dan memberikan pelayanan kepada masyarakat yang sebaik- baiknya menuju Good Governance. Pelayanan yang diberikan kepada masyarakat setiap waktu selalu menuntut pelayanan publik yang berkualitas dari birokrat yang dilakukan secara transparan dan akuntabilitas. Saat ini konsep desentralisasi dan otonomi daerah diartikulasikan oleh daerah untuk hanya berfokus pada usaha menata dan mempercepat pembangunan di wilayahnya masing- masing. Penerjemahan seperti ini ternyata belum cukup efisien dalam meningkatkan pelayanan kepada masyarakat.

Berdasarkan Undang- Undang Nomor 25 Tahun 2009 tentang pelayan publik pasal 1 ayat (1) menjelaskan bahwa pelayanan publik merupakan kegiatan atau rangkaian kegiatan dalam rangka pemenuhan kebutuhan pelayanan sesuai dengan peraturan perundangundangan bagi setiap warga negara dan penduduk atas barang, jasa dan atau pelayanan administratif yang disediakan oleh penyelenggara pelayanan publik, artinya pelayanan yang diberikan kepada masyarakat memberikan keuntungan atau dampak positif serta kenyamanan kepada pelanggan atau masyarakat, seperti halnya ketepatan waktu pelayanan, keramahan pemberi pelayanan serta fasilitas pelayanan yang memadai.

Pelayanan kepada masyarakat dapat dikategorikan efektif apabila masyarakat mendapatkan kemudahan pelayanan dengan prosedur yang singkat, cepat, tepat dan memuaskan. Keberhasilan meningkatkan efektivitas pelayanan umum ditentukan oleh faktor kemampuan pemerintah desa dalam menanamkan Budaya Kerja yang baik bagi aparat pelayanan. Budaya Kerja dalam hal ini mengarah pada standar penilaian mengenai kedisiplinan, kinerja dan kualifikasi para pelaksana pelayanan. Khususnya Aparat Kantor Desa Timoreng Panua Kecamatan Panca Rijang Kabupaten Sidenreng Rappang dituntut untuk menanamkan Budaya Kerja yang baik dalam tataran organisasinya dalam rangka meningkatkan efektivitas Pelayanan publik.

Berdasarkan hasil observasi pada tanggal 12 sampai dengan 16 November 2018 ditemukan hambatan- hambatan atau fenomena- fenomena kepegawaian masih dapat kita temui di lapangan, budaya yang telah lama mengakar dalam organisasi pemerintah desa ternyata masih sulit dihilangkan, yaitu (1) Budaya "datang terlambat pulang cepat" masih terjadi hingga saat ini, hal ini terlihat dari etos kerja, aparat yang masih sering datang terlambat diatas aturan jam kerja, sehingga jika ada masyarakat yang memliki kepentingan atau ingin mendapatkan pelayanan terpaksa harus menunggu karena kantor masih tertutup. (2) Fenomena yang lain adalah Budaya berpakaian pegawai pemerintah desa dalam penyelenggaraan pelayanan publik, terdapat beberapa pegawai pada saat ke kantor menggunakan atribut atau pakaian yang belum lengkap, yang kurang mencerminkan dirinya sebagai seseorang yang bertugas dalam melaksanakan atau memberikan pelayanan kepada masyarakat. Berdasarkan latar belakang tersebut, maka peneliti memutuskan untuk melakukan penelitian dengan judul Pengaruh Budaya Kerja terhadap Efektivitas Pelayanan Publik di Kantor Desa Timoreng Panua Kecamatan Panca Rijang Kabupaten Sidenreng Rappang dengan tujuan Untuk Mengetahui Pengaruh Budaya Kerja Terhadap Efektivitas Pelayanan Publik di Kantor Desa Timoreng Panua Kecamatan Panca Rijang Kabupaten Sidenreng Rappang, Untuk Mengetahui Faktor-faktor yang memengaruhi Budaya Kerja Terhadap Efektivitas Pelayanan Publik di Kantor Desa Timoreng Panua Kecamatan Panca Rijang Kabupaten Sidenreng Rappang.

\section{B. BUDAYA KERJA}

Menurut Hadari Nawawi (2003:65) menjelaskan bahwa Budaya Kerja adalah kebiasaan yang dilakukan berulang- ulang oleh pegawai dalam suatu organisasi. Menurut (Taliziduhu Ndraha 2003:80) "Budaya Kerja merupakan sekelompok pikiran dasar atau program mental yang dapat dimanfaatkan untuk meningkatkan efisiensi kerja dan kerjasama manusia 
yang dimiliki oleh suatu golongan masyarakat".

Menurut Edy Sutrisno (2010:171) budaya kerja diturunkan dari Budaya Organisasi. Budaya organisasi itu sendiri merupakan sistem nilai yang mengandung cita- cita organisasi sebagai sistem internal dan sistem eksternal sosial. Hal ini tercermin dari isi visi, misi dan tujuan organisasi. Dengan kata lain, seharusnya setiap organisasi memiliki identitas budaya tertentu dalam organisasinya. Menurut Mangkuprawira (2004) budaya kerja merupakan sistem nilai, presepsi, perilaku dan keyakinan yang dianut oleh setiap karyawan tentang makna kerja dan refleksinya dalam kegiatan mencapai tujuan organisasi dan individu.

Berdasarkan konsep-konsep yang telah dijelaskan di atas oleh beberapa ahli dapat disimpulkan bahwa budaya kerja merupakan suatu organisasi komitmen yang luas dalam upaya membangun sumber daya manusia, proses kerja dan hasil kerja yang lebih baik. Budaya kerja berbeda antara organisasi satu dengan yang lainnya, hal itu dikarenakan landasan dan sikap perilaku yang dicerminkan oleh setiap orang- orang dalam organisasi berbeda. Budaya kerja yang terbentuk secara positif akan bermanfaat karena setiap anggota dalam suatu organisasi membutuhkan sumbang saran, pendapat bahkan kritik yang bersifat membangun dari ruang lingkup pekerjaannya demi kemajuan sebuah organisasi, namun budaya kerja akan berakibat buruk jika pegawai dalam suatu organisasi mengeluarkan pendapat yang berbeda, hal itu dikarenakan adanya perbedaan setiap individu dalam mengeluarkan pendapat, tenaga dan pikirannya, karena setiap individu mempunyai kemampuan dan keahliannya sesuai bidang masing-masing.

Sejalan dengan hal tersebut maka teori yang digunakan untuk mengukur budaya kerja adalah teori "Budaya Kerja" menurut Taliziduhu Ndraha (2003:25) dalam bukunya Teori Budaya Organisasi. Adapun indikator budaya kerja yang akan digunakan dalam pengukuran variabel ini adalah sebagai berikut:
1. Kebiasaan: kebiasaan biasanya dapat dilihat dari cara pembentukan perilaku berorganisasi pegawai atau aparat, yaitu perilaku berdasarkan kesadaran akan hak dan kewajiban, kebebasan atau kewenangan dan tanggug jawab baik pribadi maupun kelompok didalam ruang lingkup lingkungan pekerjaan.

2. Peraturan: untuk memberikan ketertiban dan kenyamanan dalam melaksanakan tugas pekerjaan pegawai, maka dibutuhkan adanya peraturan karena peraturan merupakan bentuk ketegasan dan bagian terpenting untuk mewujudkan pegawai atau aparat yang disiplin dalam mematuhi segala bentuk peraturan- peraturan yang berlaku. Berbicara tentang peraturan, bahwa peraturan di dalam organisasi dibuat untuk menghasilkan sikap disiplin dari para aparat, oleh karenanya itu output dari pada peraturan adalah disiplin.

3. Nilai-nilai: merupakan pengahayatan seseorang mengenai apa yang lebih penting atau kurang penting, apa yang lebih baik atau kurang baik, dan apa yang lebih benar atau kurang benar.

\section{Efektivitas pelayanan publik}

Menurut Handoko

(2003:7)

"Efektivitas adalah kemampuan untuk memilih tujuan yang tepat atau peralatan yang tepat untuk mencapai tujuan yang telah ditetapkan". Sedangkan Menurut Sinambela (2011:5) pelayanan publik diartikan sebagai pemberian layanan (melayani) keperluan orang atau masyarakat yang mempunyai kepentingan pada organisasi itu sesuai dengan aturan pokok dan tata cara yang direncanakan. Jadi dapat disimpulkan bahwa efektivitas pelayanan publik adalah tercapainya suatu tujuan yang dilakukan oleh aparat dalam pelayanan sesuai dengan ketentuan yang telah ditetapkan, karena dimata masyarakat pelayanan dikatakan efektif apabila masyarakat mendapatkan kemudahan pelayanan dengan prosedur yang singkat, cepat, tepat dan memuaskan.

Kriteria atau ukuran mengenai pencapaian efektif atau tidaknya sebuah pelayanan atau pekerjaan sebagaimana 
dikemukakan oleh Richard M Steers dalam (Tangkilisan,2005:141) ada empat kriteria dalam pengukuran efektivitas kerja, yaitu:

1. Produktivitas diartikan sebagai upaya mencapai kualitas dan kuantitas suatu proses kegiatan. maka, produktivitas beriorientasi kepada bagaimana berfikir dan bertindak untuk mendayagunakan sumber masukan agar mendapat keluaran yang optimum.

2. Kemampuan adaptasi diartikan sebagai kemampuan seseorang untuk menyesuaikan diri dengan lingkungan tempat kerja, penyesuaian diri yang dapat dilakukan, yaitu dengan penyesuaian kerja dengan tingkah laku dalam menanggapi perubahan lingkungan tempat dimana kita bekerja.

3. Kepuasan kerja diartikan sebagai salah-satu aspek psikologis yang mencerminkan perasaan seseorang terhadap pekerjaannya, ia akan merasa puas dengan adanya kesusaian antara kemampuan, keterampilan dan harapannya dengan pekerjaan yang dihadapi.Dengan kondisi kerja yang positif, berarti seseorang bekerja sesuai dengan prosedur, mereka tidak menyepelekan pekerjaannya, memiliki rasa tanggung jawab yang tinggi sehingga akhirnya mencapai efektivitas yang tinggi pula.

4. Pencarian sumber daya diartikan sebagai kemampuan organisasi merekrut dan mengintegrasikan sumber daya yang baik dalam hal ini anggota organisasi sehingga mampu melaksanakn tugas dan pekerjaan dengan tepat dan mengarah pada tujuan Pelayanan yang efektif.

\section{Faktor-faktor yang memengaruhi budaya kerja Menurut Luthans dalam (Tika, 2014 :109) Faktor utama yang menentukan kekuatan budaya kerja adalah:}

1. Kebersamaan dalam artian Sejauh mana anggota organisasi mempunyai nila-nilai inti yang dianut secara bersama. Kebersamaan dalam hal ini diartikan bagaimana masing-masing anggota organisasi memiliki ikatan yang terbentuk karena rasa kekeluargaan/ persaudaraan baik itu dalam bekerja atau hubungan profesional biasa.

2. Intensitas adalah adalah derajat komitmen dari anggota- anggota organisasi kepada nilai- nilai inti budaya kerja. Derajat intensitas bisa merupakan suatu hasil kerja dari organisasi . Oleh karena itu, pimpinan perusahan / organisasi perlu memperhatikan dan mentaati struktur imbalan yang diberikan kepada anggota- anggota organisasi guna menanamkan nilai- nilai budaya kerja. Hipotesis adalah dugaan sementara oleh peneliti sebelum melakukan penelitian. Menurut Sugiyono (2009: 90) Hipotesis merupakan jawaban sementara terhadap rumusan masalah penelitian, dimana rumusan masalah penelitian telah dinyatakan dalam bentuk kalimat pernyataan.

Ho : Budaya Kerja tidak berpengaruh signifikan terhadap Efektivitas Pelayanan Publik di Kantor Desa Timoreng Panua Kecamatan Panca Rijang Kabupaten Sidenreng Rappang

Ha : Budaya Kerja berpengaruh signifikan terhadap Efektivitas Pelayanan Publik di Kantor Desa Timoreng Panua Kecamatan Panca Rijang Kabupaten Sidenreng Rappang.

\section{E. METODE PENELITIAN}

Jenis penelitian ini menggunakan tipe penelitian deskriftif kuantitaif. Populasi dalam penelitian ini seluruh (KK) di Desa Timoreng Panua Kecamatan Panca Rijang Kabupaten Sidenreng Rappang sebanyak $547 \mathrm{KK}$ dari dua dusun. Penentuan ukuran sampel penelitian menggunakan Rumus Yount dengan tingkat kesalahan $10 \%$.

pengambilan sampel dalam penelitian ini adalah Probability Sampling dengan teknik sampel acak atau Random Sampling (sebagian dari populasi). untuk dipilih menjadi sampel.

Teknik pengumpulan data yang digunakan yakni observasi, wawancara, kuisioner dan studi kepustakaan, Teknik analisis data dalam penelitian kuantitatif menggunakan statistik, data yang telah 
terkumpul akan dianalisis regresi sederhana dengan bantuan Program SPSS (Statistical Product and Service Solution) for windows.

\section{F. HASIL DAN PEMBAHASAN}

\section{Pengaruh budaya kerja terhadap efektivitas pelayanan publik}

Berdasarkan tabel model summary diperoleh nilai $\mathrm{R}$ (nilai korelasi/ hubungan) sebesar 0,750 dan nilai koefisien determinasi berganda atau $r$ square sebesar 0,563 atau $56,3 \%$ yang mengandung pengertian bahwa pengaruh variabel $X$ (budaya kerja) terhadap variabel y (efektivitas pelayanan) sebesar $56,3 \%$ sedangkan sisanya $43,7 \%$ dipengaruhi oleh faktor lain yang tidak masuk konsep dalam penelitian ini.Hasil dari uji coefficietns dikemukakan nilai konstanta (a) = 1,674 dan nilai beta (b) / koefisien regresi $=1,110$ sehingga persamaan regresi yang digunakan dalam penelitian ini dapat ditulis sebagai berikut:

$$
Y=1,674+1,110 X
$$

Dari persamaan regresi diatas dapat dijelaskan:

a. Jika variabel Budaya Kerja (X) berubah, maka efektivitas pelayanan (Y) juga akan berubah, nilai positif menunjukkan perubahan yang searah, artinya apabila Budaya kerja meningkat, maka efektivitas pelayanan juga akan meningkat sebesar nilai koefisien regresi 1,110 dan sebaliknya.

b. Nilai konstanta mengandung arti bahwa nilai konstanta variabel efektivitas pelayanan ( $\mathrm{Y}$ ) sebesar 1,674 .

c. Koefisien regresi atau nilai beta variabel $\mathrm{X}$ sebesar 1,110 menyatakan bahwa setiap penambahan $1 \%$ nilai budaya kerja/ nilai variabel $X$ ditingkatkan menjadi 1 satuan, maka nilai efektivitas pelayanan $(\mathrm{Y})$ bertambah sebesar 1,110 .

d. Koefisien regresi bernilai positif, sehingga dapat dikatakan bahwa arah pengaruh Variabel $\mathrm{X}$ terhadap $Y$ adalah Positif.
Menguji kebenaran hipotesis dalam penelitian ini dilakukan uji $\mathrm{F}$ dengan tujuan untuk mengetahui bahwa ada pengaruh yang signifikan variabel $\mathrm{X}$ terhadap $\mathrm{Y}$. Berdasarkan Hasil dari uji ANOVA pada bagian ini ditampilkan hasil yang diperoleh adalah nilai $F=68,258$ dengan tingkat probabilitas sig. 0,000. Karena nilai sig probabilitas $(0,000)<0,05$ maka keputusannya adalah variabel Budaya kerja $(X)$ mempunyai pengaruh yang signifikan terhadap variabel efektivitas pelayanan (Y). Dari hasil tersebut berarti bahwa model regresi dapat digunakan untuk memprediks efektivitas pelayanan.

Sedangkan uji statistik $t$ bertujuan untuk menunjukkan seberaoa jauh pengaruh satu variabel independen secara individual menerangkan variasi variabel dependen. Nilai $\mathrm{t}$ hitung dapat dilihat dari ouput tabel koefisien hasil olah data SPSS, sebagai berikut:

\section{Menentukan $\mathbf{t}$ hitung dan $\mathbf{t}$ tabel}

1) $t$ hitung variabel Budaya kerja (X) dari Output adalah 8,262 dengan taraf sig sebesar 0,000 (tabel Coeficient).

2) $t$ tabel dapat diketahui dari Tabel Statistik (tabel T) dengan Sig. 0,05 dan $\mathrm{df}=\mathrm{n}-2 / \mathrm{55}-2=53$ dengan pengujian 2 sisi diperoleh dari tabel $\mathrm{t}=2,672$.

\section{Menentukan Hipotesis (Ha dan Ho) \\ Ho: $b \neq 0 \quad$ : (Ho ditolak dan Ha diterima berarti ada pengaruh $X$ terhadap $Y)(\mathrm{Ha})$. \\ $\mathrm{Ho}: \mathrm{b}=0$ : (Ho diterima dan $\mathrm{Ha}$ ditolak berarti tidak ada pengaruh $\mathrm{X}$ terhadap $\mathrm{Y})(\mathrm{Ho})$.}

\section{Hipotesis dalam bentuk kalimat:}

a. Hipotesis Ha: Budaya kerja berpengaruhsignifikanterha dap Efektivitas pelayanan publikdi kantor Desa 
Timoreng

Panua

Kecamatan Panca Rijang

Kabupaten Sidenreng

Rappang.

b. HipotesisHo :Budaya kerja tidakberpengaruhsignifikant erhadap Efektivitas pelayanan publik di kantor Desa Timoreng Panua Kecamatan Panca Rijang Kabupaten Sidenreng Rappang.

\section{Kaidah keputusan :}

a. Jika nilai $t$ nitung $\mathrm{t}$ tabel , maka $\mathrm{Ho}$ ditolak dan $\mathrm{Ha}$ diterima, artinya siginifikan

b. Jika nilai $t_{\text {hitung }}<t_{\text {tabel, }}$ maka Ho diterima dan Ha ditolak, artinya tidak signifikan

\section{Pengambilan Keputusan :}

$\mathrm{t}_{\text {Hitung }}>\mathrm{t}$ Tabel Ho ditolak

$8,262>2,672$ maka, Ho ditolak

Kesimpulan :

Karna $t$ Hitung $(8,262)>t$ Tabel $(2,672)$ jadi Hipotesis Ho ditolak dan $\mathrm{Ha}$ diterima artinya signifikan, kesimpulannya Budaya kerja berpengaruh signifikan terhadap Efektivitas pelayanan publik di kantor Desa Timoreng Panua Kecamatan Panca Rijang Kabupaten Sidenreng Rappang . Pengaruhnya Positif karna Koefisien dan $\mathrm{t}$ Hitungnya positif, artinya jika Budaya kerja Meningkat maka efektivitas pelayanan juga meningkat.

\section{Faktor-faktor yang memengaruhi budaya kerja}

Berdasarkan tabel model summary koefisien faktor kebersamaan terhadap efektivitas pelayanan publik di Desa Timoreng Panua Kecamatan Panca Rijang Kabupaten Sidenreng Rappang berada pada persentase $23,3 \%$. Sedangkan faktor intensitas terhadap efektivitas pelayanan publik di Desa Timoreng Panua Kecamatan Panca Rijang
Kabupaten Sidenreng Rappang berada pada persentase $30,2 \%$. Dari kedua faktor diatas dapat dilihat bahwa faktor intensitas lah yang paling berpengaruh yaitu sebesar 30,2 \% sehingga dapat disimpulkan bahwa pegawai harus lebih memperhatikan ketepatan waktu dalam menyelesaikan tugas dan pekerjaan yang telah menjadi tanggung jawabnya masingmasing.

\section{G. KESIMPULAN}

Berdasarkan hasil penelitian yang telah diuraikan pada bab sebelumnya dapat disimpulkan bahwa:

1. Budaya Kerja terhadap Efektivitas Pelayanan Publik di Kantor Desa Timoreng Panua Kecamatan Panca Rijang Kabupaten Sidenreng Rappang memiliki pengaruh yang signifikan dengan melihat dari hasil olahan data pada tabel ANOVA, dimana nilai $t$ Hitung $(8,262)>t$ Tabel $(2,672)$ dengan tingkat signifikansi $0,000 \quad(\mathrm{~F}<$ 0,05), maka Ho ditolak dan $\mathrm{Ha}$ diterima artinya Budaya Kerja (X) berpengaruh signifikan terhadap efektivitas pelayanan publik (Y).

2. Berdasarkan tabel Model Summary diperoleh nilai $r$ square sebesar 0,563 atau $56,3 \%$, artinya besar pengaruh Budaya kerja (X) terhadap Efektivitas pelayanan Publik (Y) di Kantor Desa Timoreng Panua Kecamatan Panca Rijang Kabupaten Sidenreng Rappang sebesar $56,3 \%$ kategori "Cukup berpengaruh"

3. Faktor-faktor yang memengaruhi budaya kerja dapat dilihat dari faktor yang pertama yaitu kebersamaan memiliki pengaruh sebesar $23,3 \%$. Faktor yang kedua yaitu intensitas memiliki pengaruh sebesar $30,2 \%$.

\section{H. REFERENSI}

Handoko, Handayadiningrat, Dkk. 2003. Manajemen Sumber Daya Manusia 
Edisi Revisi. Jakarta: PT. Rineka Cipta.

Jamaluddin, Ahmad. 2015. Metode Penelitian Administrasi Publik. Gava Media. Yogyakarta.

Mangkuprawira, S. 2004. Manajemen Sumber Daya Manusia Strategis. Bogor: Ghalia Indonesia.

Ndraha,Taliziduhu. 2003. Teori Budaya Organisasi cetakan kedua. Jakarta: PT Rineka cipta.

Nawawi, H. 2003. Manajemen Sumber Daya Manusia. Yogyakarta: Gajah Mada Univercity Press.

Pabundu Tika, Moh. 2014. Budaya Organisasi dan Peningkatan Kinerja Perusahaan. Bumi Aksara: Jakarta.

Sugiyono. 2009. Metode Penelitian Administrasi. Bandung. Alfabeta Sutrisno, E. 2010. Budaya Organisasi. Jakarta: Kencana.

Sinambela, Lijan Poltak dkk. 2011. Reformasi Pelayanan Publik. Jakarta: Bumi Aksara.

Tangkilisan, Nogi Hersel. 2005. Manajemen Publik. Jakarta: PT. Gramedia Widiasarana Indonesia

Dokumen - Dokumen :

Undang - Undang Nomor 25 Tahun 2009 tentang "Pelayan Publik" 